\title{
Informants' Traits Weigh Heavily in Young Children's Trust in Testimony and in Their Epistemic Inferences
}

\author{
Jonathan D. Lane, Henry M. Wellman, and Susan A. Gelman \\ University of Michigan
}

\begin{abstract}
This study examined how informants' traits affect how children seek information, trust testimony, and make inferences about informants' knowledge. Eighty-one 3- to 6-year-olds and 26 adults completed tasks where they requested and endorsed information provided by one of two informants with conflicting traits (e.g., honesty vs. dishonesty). Participants also completed tasks where they simultaneously considered informants' traits and visual access to information when inferring their knowledge and trusting their testimony. Children and adults preferred to ask and endorse information provided by people who are nice, smart, and honest. Moreover, these traits influenced the knowledge that young children attributed to informants. Children younger than 5 years of age reported that people with positive traits were knowledgeable even when they lacked access to relevant information.
\end{abstract}

Much of the knowledge that children and adults hold is derived from information others provide. From others, we acquire information ranging from the mundane- - today's date or the weatherto information that cannot be easily observed or assessed-the presence of germs, the existence of God, or the nature of the afterlife (Harris \& Koenig, 2006). Given young children's limited experience with the world, testimony is a particularly valuable source of information for them (Gelman, 2009; Harris, 2007). But not all people are sources of reliable information. Some people unknowingly offer inaccurate information because of their own misperceptions or ignorance. Others intentionally (perhaps malevolently) provide false information. Because of this variability in informants' trustworthiness, it is important for children to be selective in whom they

Funding for this research was provided by National Institute of Child Health and Human Development Grant HD022149 to Henry Wellman and by Rackham School of Graduate Studies Research Grant to Jonathan Lane. We are very grateful to the children and parents who participated in this study and to the administration, teachers, and staff at the University of Michigan Children's Centers and Go Like the Wind Montessori School. We appreciate Becca Leider for her help interviewing children, and Daniel Blumer, Jennifer Elledge, and Amanda Nagrotsky for their help entering and checking data. The manuscript benefited from feedback provided by Vikram Jaswal and other members of International Max Planck Research School on the Life Course, and benefited from comments and suggestions provided by four anonymous reviewers. A portion of this research was presented at the annual meeting of the Association for Psychological Science, May 2010.

Correspondence concerning this article should be addressed to Jonathan D. Lane, Harvard Graduate School of Education, Cambridge, MA 02138. Electronic mail may be sent to jonathan lane@gse.harvard.edu. choose to learn from. The current study examines how informants' traits-specifically, their smartness, kindness, and honesty-affect how children seek information, trust testimony, and make inferences about informants' knowledge.

Preschool-age children appreciate that people possess traits-intangible, stable dispositions that guide thinking and behavior (for a review, see Heyman, 2009) —and indeed young children can use others' traits to predict their psychological experiences and behavior (Heyman \& Gelman, 1999, 2000; Liu, Gelman, \& Wellman, 2007). How children consider informants' traits when acquiring knowledge is a critical issue to address because the people from whom children typically learn are people with whom children have extensive experienceparents, friends, teachers-and thus children have substantial information about those individuals' stable characteristics. Harris (2007) argues that children create "cognitive profiles" of informants:

They form a global impression of each individual, regarding some as more epistemically trustworthy than others. We assume that this global impression regarding any given informant is based on some kind of aggregated metric. Information about the informant's past inaccuracy, ignorance, uncertainty, or apparent idiosyncrasy is fed into that profile. (Harris, 2007, p. 138)

(C) 2012 The Authors

Child Development (c) 2012 Society for Research in Child Development, Inc. All rights reserved. 0009-3920/2013/8404-0011

DOI: $10.1111 /$ cdev.12029 
Much of the recent work on children's trust in testimony examines how one potentially traitrelated characteristic - informants' accuracy-affects the way that children learn from others. In one standard task, children are shown two characters, typically hand puppets or real people on video (Clément, Koenig, \& Harris, 2004; Koenig, Clément, \& Harris, 2004; Koenig \& Harris, 2005), who differ in their demonstrated accuracy (e.g., their correct or incorrect naming of common objects) and children choose to ask one character to learn something new (e.g., the name of a novel object). Then both characters offer conflicting information (testimony) and children choose which character's testimony they believe by endorsing one or the other. When learning the names of novel objects, 3- and 4-year-olds prefer to ask previously accurate informants (Koenig et al., 2004). Four-year-olds additionally prefer to endorse object labels provided by accurate informants (Clément et al., 2004; Koenig et al., 2004).

Although 3-year-olds often do not preferentially endorse accurate informants' testimony in these tasks, those who keep better track of informants' prior accuracy more often endorse testimony provided by more accurate informants (Koenig et al., 2004). Three-year-olds also selectively endorse informants when presented more data about informants' tendencies. In cases where young children see one informant is consistently accurate across three or four instances, and the other informant is inaccurate across three or four instances, even 3-year-olds trust testimony provided by the previously accurate informant (Birch, Vauthier, \& Bloom, 2008; Pasquini, Corriveau, Koenig, \& Harris, 2007; Scofield \& Behrend, 2008). However, if both informants are wrong at least once (e.g., one is correct $25 \%$ of the time whereas the other is correct $75 \%$ of the time), 3-year-olds no longer demonstrate selective trust; 4-year-olds do (Pasquini et al., 2007). Thus, 3 -year-olds in particular seem to require consistent evidence about informants' tendencies (in this case, their accuracy) in order to develop a profile of an "accurate" or "inaccurate" informant.

Being accurate or inaccurate is not a trait per se, and this is something that even preschoolers realize. For example, preschoolers are willing to trust recently inaccurate informants if their inaccuracies stem from ignorance or false beliefs (Nurmsoo \& Robinson, 2009; Robinson \& Nurmsoo, 2009) -in these cases, it is clear that inaccuracy does not indicate a broad, trait-like mental shortcoming. However, systematic accuracy might be related to underlying traits, such as intelligence. Given their inductive potential (Heyman, 2009) traits may exert a particularly powerful influence on children's trust in certain informants; however, this possibility is largely unaddressed in the literature. The aforementioned studies collectively show that the stronger the evidence about informants' systematic accuracy, the more heavily children weigh that tendency when trusting testimony. Thus, characters' enduring, underlying traits may be especially effective in eliciting selective trust from young children. These considerations framed our methods in the current study. Children saw two informants who differed in the accuracy of their prior testimony (as in Koenig et al., 2004; Koenig \& Harris, 2005). Importantly, children also received additional information about these informants' traits that might influence the quality of their testimony; for example, the informants were assigned the trait labels "smart" and "not smart," we described what both of those labels mean, then reminded children that the informants possess those traits and checked that children understood.

In addition to smartness, we examined whether and when young children take into account other traits, specifically kindness and honesty. Kindness (being mean or nice) was included because it is a trait understood even by young preschoolers; they appreciate that nice and mean people engage in different behaviors and have different motives (Heyman \& Gelman, 1999, 2000). Although, for adults, kindness does not necessarily reflect the quality of one's epistemic states, because it has an emotional component and because it may influence children's global evaluations of individuals, kindness may nonetheless influence children's selective trust. Honesty has strong emotional appeal as well, and is also a characteristic that young children are beginning to understand. Preschoolers are sensitive to statements that are lies and in some studies even 3-year-olds understand lying as a psychological process (Siegal \& Peterson, 1996, 1998). In addition to its potential emotional appeal, honesty may directly reflect the quality of information someone is likely to produce, so it is a particularly important trait to consider when assessing testimony. Conceivably, whether informants are generally dishonest (or honest) could influence young children's willingness to trust their testimony.

In the prior work examining the influence of informants' kindness and honesty on children's trust, Mascaro and Sperber (2009, Studies 2 and 3) had a single informant (a frog puppet) provide young children with erroneous testimony about the location of candy. In one study, the informant was described as a "Big liar! It always tells lies." In the 
other study, the informant was described as "Very mean! It does not want you to find the sweet!" In both studies, children were presented two boxes and the informant made a claim that the candy was in one of the boxes. It was not until age 4 years in Study 2 (and still later in Study 3) that children avoided the box indicated by the deceptive frog. However, these results may not reflect children's consideration of informants' honesty in particular. In their Study 2, children were warned about the informant ("Watch out!") as well as told he was a liar, so it is not clear if 4-year-olds' appropriate choices reflect the warning, the lying, or both. Moreover, these results likely reflect young children's more general difficulty disregarding claims or instructions given by a single informant, regardless of his characteristics. This tendency is particularly strong when informants provide spoken information (Jaswal, Croft, Setia, \& Cole, 2010; Reed, Pien, \& Rothbart, 1984; Strommen, 1973; Vanderbilt, Liu, \& Heyman, 2011). Prior studies seem to indicate that children's sensitivity to characteristics of informants (e.g., accuracy, age) is most clearly demonstrated when children choose between the conflicting testimony of two informants (Jaswal \& Neely, 2006; Koenig et al., 2004; Pasquini et al., 2007). Indeed, when Mascaro and Sperber (2009) described a single deceptive informant as "mean" in their Study 3, preschoolers still followed his testimony, even though 3-year-olds preferred the testimony of a nice informant (rather than the testimony of a mean informant) in their Study 1 . Thus, almost no research has addressed children's appreciation for informants' honesty when learning from others, and the available data may underestimate children's understanding. Here, we employ a standard testimony paradigm-having children choose between honest and dishonest informants who offer conflicting information-to examine whether young children weigh informants' honesty when learning from others.

In summary, we comprehensively compare the influence of several different traits - smartness, kindness, and honesty - on how children seek and endorse information provided by others. All of these traits are worth considering when learning from others, but the developmental point at which children begin to take them into consideration may differ.

Of note, young children's performance in prior studies varies depending on the nature of the task: including whether there is a single or multiple informants (Mascaro \& Sperber, 2009) and, of particular relevance to the current study, if children are to ask versus endorse informants. For example, as Koenig et al. (2004) demonstrated, 3-year-olds prefer to ask a recently accurate (vs. inaccurate) person for information, but are equally likely to endorse the two informants' subsequent testimony. This may be because the two tasks differ in what they assess, with the former potentially measuring a global attraction (or aversion) to an informant or a desire to affiliate with one informant over the other, and the latter a more direct measure of children's consideration of the actual information that people offer. This distinction is especially important to consider when informants have positive and negative traits. Thus, we include both types of questions in the current study: ask (Who will you ask for information, $\mathrm{X}$ or $\mathrm{Y}$ ?) and endorsement (Do you believe X's or Y's testimony?).

\section{Preference for Information Versus Desire to Affiliate}

The affiliation possibility, just discussed, deserves further attention. Some have challenged the notion that children's choice of informants and information on standard testimony tasks actually reflects children's consideration of informants' epistemic states (e.g., Lucas \& Lewis, 2010). One alternative possibility is that children's responses to both ask and endorsement tasks reveal nothing more than a general attraction to certain people, rather than an appreciation for the quality of information the people have to offer. Several studies in which accurate informants are pitted against inaccurate informants demonstrate that children's preference for testimony is not based on a general attraction to accurate informants (e.g., Birch et al., 2008; Jaswal \& Neely, 2006). However, informants in the current study have strongly valenced traits (e.g., meanness and niceness) which may more strongly influence informants' global attractiveness to children. Thus, in addition to comparing children's performance across the ask and endorsement tasks, we also directly assess children's general attraction to each informant by having children report whether they would like to be friends with each informant. This allowed us to assess relations between children's general attraction to certain people and their tendency to ask and endorse information provided by those same people.

Even if not driven solely by a general attraction to certain informants, perhaps initially children weigh informants' more global characteristics (e.g., traits) over more proximate factors (e.g., informants' current epistemic states) when deciding whose information to trust. Alternatively, as we discuss next, informants' more enduring, global qualities 
may influence children's inferences about informants' epistemic states, and this in turn may influence whose testimony children trust.

\section{Considering Informants' Knowledge}

One goal of research on children's trust in testimony is to understand when children appreciate that certain people possess better knowledge than others. Theoretically, the nature of informants' traits may not matter if they are ignorant -if they lack the knowledge that a learner wants to acquire. An ignorant person's testimony may be untrustworthy, regardless of whether he is intelligent, kind, or honest. However, traits carry strong inductive potential and may lead children astray when making inferences about epistemic states. Because children often form global evaluations of individuals (as good or bad) across multiple domains (Alvarez, Ruble, \& Bolger, 2001; Cain, Heyman, \& Walker, 1997; Stipek \& Daniels, 1990), positive traits may suggest to young children that informants are generally knowledgeable even when they are not. So, in examining their understanding of the relevance of various traits for testimony, it is important also to assess children's understanding of informants' knowledge.

Prior work indicates that young children are appropriately sensitive to informants' knowledge in certain scenarios. For example, children as young as 3 years of age are less willing to believe the testimony of someone who is ignorant because he lacks visual access to relevant information (Robinson, Champion, \& Mitchell, 1999). If faced with a scenario in which one informant accurately labels common objects and the other informant consistently says "I do not know," 3-year-olds prefer to ask the accurate informant for the label of a new object, and 4-year-olds prefer to ask and endorse labels provided by the (thus far) accurate informant (Koenig \& Harris, 2005). Four-year-olds are also more accepting of information provided by informants who are confident in their knowledge (Moore, Bryant, \& Furrow, 1989). For example, they believe information provided by someone who says, "I know it is in the red box" versus someone who says, "I guess it is in the red box" (see also Jaswal \& Malone, 2007; Sabbagh \& Baldwin, 2001). Building on these beginnings, more information is needed about how informants' access to knowledge affects children's trust in testimony, particularly in relation to their appreciation for traits such as smartness, which may also convey to young children information about knowledge.
In the current study, our approach to these issues is to assess how children simultaneously consider informants' traits and their access to contextspecific information. In real life, these factors do not always converge: A "good" person is sometimes ignorant; a "bad" person may be knowledgeable (e.g., an accessory to a crime). This interplay between traits and knowledge may be problematic for preschoolers, and understanding how children negotiate such situations may provide important information about the development of trust in testimony. For example, if preschoolers prefer the testimony of well-informed people (e.g., Robinson et al., 1999), they may continue to favor their testimony even if those informants possess negative traits. In contrast, certain traits may overinfluence children's inferences about the quality of informants' knowledge and also their subsequent decisions about who to trust. Moreover, how children simultaneously weigh informants' traits and knowledge access may vary depending upon the trait. For example, smartness may be weighted more heavily than niceness, because smartness links more directly to knowledge states. To examine these as-yet-untested possibilities, we asked children to decide between the testimony of positive-trait informants who are poorly informed versus negativetrait informants who are well informed.

In summary, the current study is designed to address four questions: (a) How do informants' traits-specifically, their honesty, kindness, and smartness-influence young children's choice of informants and trust in their testimony? (b) Is children's preference for informants with certain traits based solely on a desire to affiliate with those informants? (c) How do informants' traits influence children's inferences about their knowledge? and (d) How do children simultaneously weigh informants' traits and their knowledge when trusting testimony?

\section{Method}

\section{Participants}

Participants included 94 children between 3 and 6 years of age. Of these children, six were not included in our analyses because they ended the interview session early (three 3-year-olds, two 4year-olds, and one 5-year-old) and another seven (six 3-year-olds and one 4-year-old) were excluded because they failed to remember which trait corresponded to each of the characters. The final sample consisted of 81 children, including twenty-five 
3-year-olds $(14$ girls, 11 boys; range $=34.57-$ 48.77 months, $M=41.91$ ), thirty-two 4-year-olds (12 girls, 20 boys; range $=49.20-59.83$ months, $M=54.58)$, and twenty-four 5- and 6-year-olds (11 girls, 13 boys; range $=61.03-82.50$ months, $M=69.77)$. Children were interviewed for approximately $20 \mathrm{~min}$ in a quiet, familiar room in their school. Children attended schools in a Midwestern university town, were primarily White, and were of middle to upper-middle socioeconomic status. When parents gave permission, interviews were audio recorded. To assess what a mature pattern of responses would be for our tasks, 26 adults (15 women, 11 men; age range $=18$ to 79 years, $M=34.77)$ completed an online version of the study with identical characters, scenarios, and questions.

\section{Measures and Procedure}

Children heard three pairs of stories (presented in story books) in which two pictured characters exhibited contrasting traits: Honest-dishonest, nicemean, and smart-not smart. The six stories and pictures are presented in the Appendix. To maximize children's understanding of these characters' traits as enduring, stable qualities and not fleeting characteristics, children were given multiple converging pieces of information about each character. For each character, children were given a trait label (e.g., "Sam is smart"), description of the trait (e.g., "Sam is a boy who gives right answers"), scenario (e.g., Sam correctly identifying that an animal is a frog), and reminder about the trait (e.g., "Remember, Sam is smart"). Interviewers were careful to use a similar intonation during the presentation of all characters. The order in which the trait pairs were presented, the order in which characters were presented within pairs, and characters' appearance/name within pairs were counterbalanced. For each trait pair, children were shown laminated drawings of both characters and were asked to recall which trait corresponds to each character (e.g., "Which one is smart, Sam or Noah?" and "Which one is not smart, Sam or Noah?"). These memory checks were administered twice for each pair: immediately after a pair was introduced and half-way through the set of questions for that pair. Corrective feedback was provided when necessary. Children who were incorrect for both memory checks for any of the traits were excluded from analyses.

Following the presentation of each character, children were asked whether they wanted to be friends with him (affiliation questions). For each of the three trait pairs, children were given three tasks (numbered below as 1, 2, 3), each containing two elements. (1) Object naming: (a) asking one of the two informants about the name of a novel object, (b) endorsing one informant's testimony about the object's name; (2) Box contents: (a) asking one of the two informants about the contents of a box that both characters looked inside, (b) endorsing one informant's testimony about the box's contents; (3) Knowledge: (a) judging which character is knowledgeable about the contents of a closed box when only one character (the negativetrait character) has looked in the box, (b) endorsing testimony from one of the two informants about the contents of the closed box. The order of the three tasks was counterbalanced, and within trait pairs, location/presentation order (left/first or right/second) was counterbalanced. For all of these tasks, characters were presented as drawings on laminated cards (the same cards used for the memory checks described above). Characters were voiced by the experimenter and their actions (e.g., approaching and opening boxes) were illustrated by the experimenter manually moving the drawings. Additional details of these procedures are provided below.

Affiliation. To assess children's desire to affiliate with each character, following each character's introduction, children were asked, "Would you like to be friends with (character's name)?"

Object naming. Children were shown a picture of a novel object situated between the two informants and were asked, "Do you know what this is called?" The majority of the children said "No." Children were then told, "You can ask (first informant) or (second informant) what this is called. Who do you want to ask?" Both characters offered a label and children were asked: "What do you think this is called, (first informant's label) or (second informant's label)?"

Box contents (open box). Children were shown an open box (with the opening facing away from the child) and were asked, "Do you know what is inside this box?" Most children replied "No." Children were then told, "(First informant) and (second informant) are going to look in the box." Both characters leaned over the box and children were told, "Let us find out what is inside. Who do you want to ask, (first informant) or (second informant)?" Both characters offered an answer (the name of a familiar object) and children were asked, "What do you think is inside, (first informant's answer) or (second informant's answer)?" 
Knowledge (closed box). For each trait pair, children also received a task in which the negative-trait character (dishonest, mean, not smart) looked inside a box, and the positive-trait character (honest, nice, smart) did not. So the valence of the trait conflicted with the informants' access to knowledge. For each trait-pair, children were shown a closed box and were asked, "Do you know what is inside this closed box?" and "Can you see inside this box?" Most children answered "No" to both questions. Next, children were told: "(Positive-trait character) and (negative-trait character) have never ever seen inside this closed box before. Now, (positive-trait character) picks up the closed box, walks, and puts it down over here. (Negative-trait character) opens the box, looks inside, and then closes the box." Children were then asked the focal question: "Who knows what is inside the box, (positive-trait character) or (negative-trait character)?" For each trait pair, the order in which the characters acted on the box was counterbalanced.

In order to examine how children simultaneously weigh informants' traits and their access to knowledge, we had children choose between testimony offered by the two informants: negative-trait informants with access to knowledge and positive-trait informants without access to knowledge. Thus, following children's decisions about the informants' knowledge in this task, both characters made claims about the box's supposed contents (offering the name of a familiar object), and children were asked, "What do you think is inside, (first informant's answer) or (second informant's answer)?"

\section{Results}

Preliminary analyses revealed no gender differences in children's performance on our tasks. Thus, data from girls and boys were combined in the following analyses.

\section{Asking Informants for Information}

We first report children's decisions to seek information from certain people. Children's decisions to ask certain informants for information were comparable when learning the name of the novel object and when learning the contents of the open box that both informants looked inside. Thus, children's performance was averaged across the two tasks. For each trait pair, children could earn a score ranging from $0 \%$ (never asked the positive-trait character) to $100 \%$ (asked the positive-trait character on both tasks). Figure 1 depicts children's decisions to seek information from each of the positive-trait informants. An initial 3 (trait) $\times 3$ (age group) analysis of variance (ANOVA) examining children's decisions to ask the informants with positive traits (i.e., the honest, nice, and smart informants) revealed a significant effect of age group, $F(2$, $78)=5.17, p<.01$, but no significant effect of trait or interaction between age group and trait. Fiveand six-year-olds $(M=95 \%, S D=13 \%)$ asked the positive-trait informants significantly more often than did 3-year-olds $(M=77 \%, S D=24 \%, p<.01$ according to Tukey's honestly significant difference [HSD] pairwise comparisons), and marginally more often than did 4-year-olds $(M=83 \%, S D=23 \%$, $p=.07$ according to Tukey HSD pairwise comparisons).

Analyses within each age group revealed that when presented informants who possessed stable underlying traits, children as young as 3 years preferred to ask the nice (vs. mean) informant: 3-year-olds, $t(24)=3.36, p<.01 ; 4$-year-olds, $t(31)=$ $7.00, p<.001$; and 5- to 6-year-olds, $t(23)=12.69$, $p<.001$. More novel to our study was the inclusion of a pair of informants who differed in their smartness and another pair who differed in their honesty. We found that 3-year-olds, $t(24)=3.38, p<.01 ; 4$ year-olds, $t(31)=6.17, p<.001$; and 5 - to 6-yearolds, $t(23)=15.91, p<.001$, asked the smart (vs. not smart) informant above chance, and that children as young as 3 years also preferred to seek information from the honest (vs. dishonest) informant: 3-year-olds, $t(24)=5.20, p<.001 ; 4$-year-olds, $t(31)=4.72, \quad p<.001$; and 5- to 6-year-olds, $t(23)=15.91, p<.001$. Thus, informants' smartness, kindness, and honesty all significantly influence who young children choose to learn from, and the influence of these traits increases throughout the preschool years.

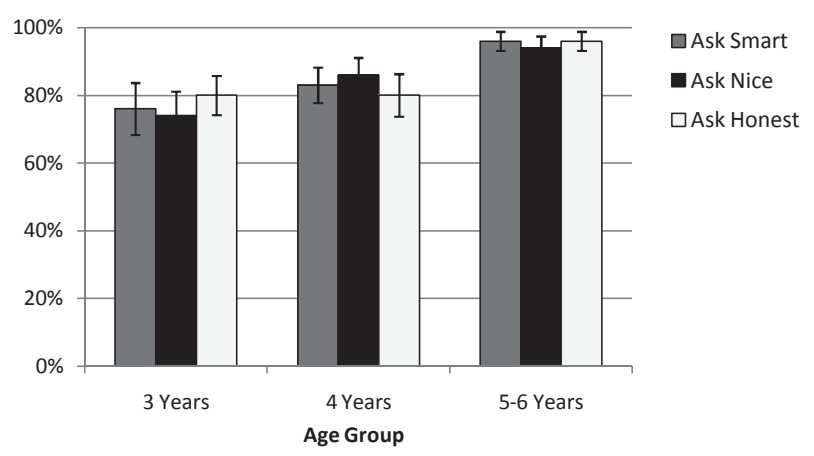

Figure 1. Percentage of decisions to ask the positive-trait characters (smart, nice, and honest) for information, per age group. 


\section{Endorsing Informants' Testimony}

As noted in the Introduction, asking one informant over another may be a measure of a desire to affiliate as much as an evaluation of testimony and particularly if children are given trait information about the informants. Thus, it is important to also consider endorsement - a task that might more directly gauge children's appreciation for the quality of the information rather than for the informants themselves. For each trait pair, for both object-naming and box-contents tasks, after children chose to ask one informant, both informants offered testimony (labels for the novel object or names of the object contained in the box) and children endorsed one informant's testimony. Children's decisions about which informant's testimony they trusted were comparable in both tasks, so we again averaged children's performance across the two tasks. For each trait pair, children could earn a score ranging from $0 \%$ (never endorsed positive-trait character's testimony) to $100 \%$ (endorsed positivetrait character's testimony on both tasks).

Figure 2 illustrates children's decisions to endorse testimony provided by each of the positive-trait informants. An initial 3 (trait) $\times 3$ (age group) ANOVA assessed children's endorsement of testimony provided by the positive-trait informants. This analysis revealed a significant effect of age group, $F(2,78)=10.91, p<.001$, but no significant effect of trait or interaction between age group and trait. Five- and 6-year-olds $(M=96 \%, S D=14 \%)$ endorsed the positive-trait informants' testimony significantly more often than did 3-year-olds $(M=67 \%, S D=27 \%, p<.001$ according to Tukey HSD pairwise comparisons) and 4-year-olds $(M=74 \%, S D=24 \%, p<.01$ according to Tukey HSD pairwise comparisons).

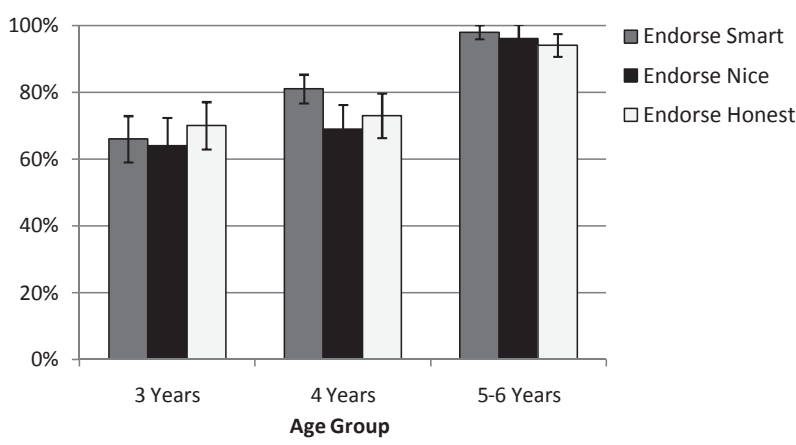

Figure 2. Percentage of decisions to endorse information provided by the positive-trait characters (smart, nice, and honest), per age group.
Considering first nice versus mean informants, 4-year-olds, $t(31)=2.55, p<.05$, and 5- to 6-yearolds, $t(23)=11.00, p<.001$, endorsed the information provided by the nice informant above chance, and 3-year-olds tended in that direction, $t(24)=$ $1.66, p=.11$. More novel to our study was the inclusion of informants who differed in their smartness and honesty. When smartness was presented as a stable underlying trait, children as young as 3 years of age endorsed testimony provided by the smart (vs. not smart) informant above chance: 3-year-olds, $t(24)=2.32, p<.05 ; 4$-year-olds, $t(31)$ $=7.19, p<.001$; and 5- to 6-year-olds, $t(23)=23.00$, $p<.001$. Moreover, children as young as 3 years of age preferred testimony provided by the honest (vs. dishonest) informant above chance: (3-year-olds, $t(24)=2.83, p<.01 ; 4$-year-olds, $t(31)=3.48$, $p<.01 ;$ and 5 - to 6-year-olds, $t(23)=12.69$, $p<.001$. Though 3-year-olds did not endorse the nice informant's testimony above chance, their preference for his testimony did not differ significantly from their preference for the smart or honest informant's testimony, $F(2,23)=.17$, ns. In summary, informants' smartness, honesty, and (to a lesser extent) their kindness influence children's trust in testimony. These effects emerge as early as age 3 and become more pronounced throughout the preschool years.

If children's decisions to ask an informant were influenced by their general attraction to him without regard for his epistemic states, this might be especially the case for a trait such as niceness (kindness). Indeed, with regard to the least epistemically relevant trait, kindness, children were more likely to ask the nice informant $(85 \%)$ than they were to endorse his subsequent testimony (75\%), $t(80)=2.15, p<.05$. In contrast, for smartness and honesty, children's decisions about whose testimony to endorse were equivalent in frequency to their decisions about who to ask-children were equally likely to ask the smart informant $(84 \%)$ and to endorse his testimony $(81 \%), t(80)=.74, n s$, and were equally likely to ask the honest informant $(85 \%)$ and to endorse his testimony $(78 \%), t(80)=$ $1.43, n s$. These data are relevant for an "affiliation" hypothesis, which we examined more directly by asking children whether they would like to be friends with each of the characters.

\section{Affiliation with Informants}

As shown in Figure 3, 4- through 6-year-olds wanted to be friends with all of the positive-trait characters (smart, nice, honest), but not with any 


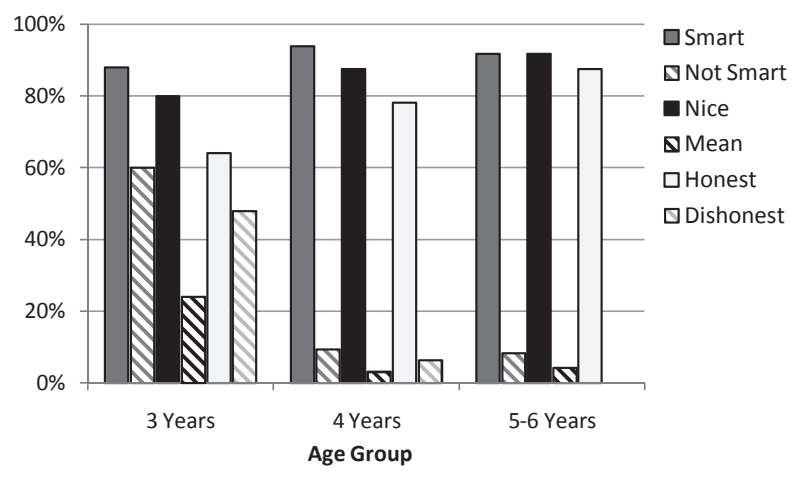

Figure 3. Percentage of children who chose to be friends with each of the characters, per age group.

of the negative-trait characters (not smart, mean, dishonest). Three-year-olds exhibited a different pattern. Like the older children, 3-year-olds wanted to be friends with the nice character but not with the mean character. However, in contrast to older children, roughly half of the 3-year-olds wanted to be friends with informants who were dishonest or not smart. Further, there was no statistical difference in 3-year-olds' decisions to be friends with the honest versus the dishonest character, $\chi^{2}(1)=1.50, n s$.

This pattern of results provides a direct test of the affiliation hypothesis. Suppose children's trust merely reflects a desire to affiliate with or a general attraction to certain informants. Then, given 3-yearolds' overwhelming desire to affiliate with the nice (and not the mean) informant and the minimal difference in their desire to affiliate with the smart (vs. not smart) informant or with the honest (vs. dishonest) informant, they should selectively trust nice over mean informants but show a different pattern of trust for the smart-not smart pair and the honest-dishonest pair. However, the 3-year-olds were equally willing to ask and to endorse information from the nice, smart, and honest characters: ask, $F(2,23)=.38$, ns, and endorse: $F(2,23)=.17$, ns.

More generally, across all participants, a sizable number of children $(n=19)$ reported not wanting to be friends with the honest character (often indicating that they chose to not be friends with him because he violated a social norm by breaking a window). If children's trust simply reflects a desire to affiliate with or general attraction to the honest (vs. dishonest) character, then these children should trust the honest character less than children who did want to be his friend $(n=62)$. However, these two groups of children were equally likely to ask the honest informant, $t(79)=.96, n s$, and to endorse his testimony, $t(79)=1.50, n s$. Moreover, children's preference to ask and endorse information provided by the honest informant was above chance even for children who did not want to be friends with him: ask, $t(18)=3.64$, $p<.01$, and endorse, $t(18)=2.11, p<.05$.

Finally, for each age group, we conducted correlations between children's desire to be friends with positive-trait informants (a score of $0-3$ ) and negative-trait informants (a score of $0-3$ ) on the one hand, and their tendency to ask and endorse the positive-trait informants on the other. Among 3-year-olds, many of whom chose to be friends with positive- and negative-trait informants, friendship choices were unrelated to their decisions to ask and to endorse the positive-trait informants. Among older children, who typically only wanted to be friends with positive-trait informants, friendship choices were also unrelated to their endorsement of the positive-trait informants' testimony. In these analyses, friendship choice was only related to older children's decisions about who to ask for information: Children who wanted to be friends with fewer negative-trait characters were more likely to ask the positive-trait informants for information: 4-year-olds, $r(30)=-.56, p<.001$, and 5- to 6-year-olds, $r(22)=-.66, p<.001$. In summary, it is unlikely that children's trust in testimony in the current study solely reflects an overwhelming general attraction to these positive characters or a general aversion to the negative characters.

\section{Considering Informants' Knowledge}

Potentially, others' traits may influence more than just children's decisions about whose testimony they should seek and endorse. Given their strong inductive potential, traits may influence the very knowledge children attribute to informants. We examined this possibility with the knowledge task in which the negative-trait characters looked inside a closed box (so they had knowledge of the box's contents) and the positive-trait characters did not look in the box (so they were ignorant about the box's contents). Thus, the quality of knowledge conflicted with the valence of the trait. Children were asked which character knows what is inside the box. Across the entire sample, correct attributions of knowledge to the negative-trait characters did not vary between the three trait pairs (Cochran's $\mathrm{Q}=.267, n s$ ). Thus, we averaged across all three trait pairs, so children could earn scores ranging from $0 \%$ (never attributed knowledge to negative-trait characters) to $100 \%$ (attributed knowledge to all three negative-trait characters). Figure 4 depicts children's correct attributions of 


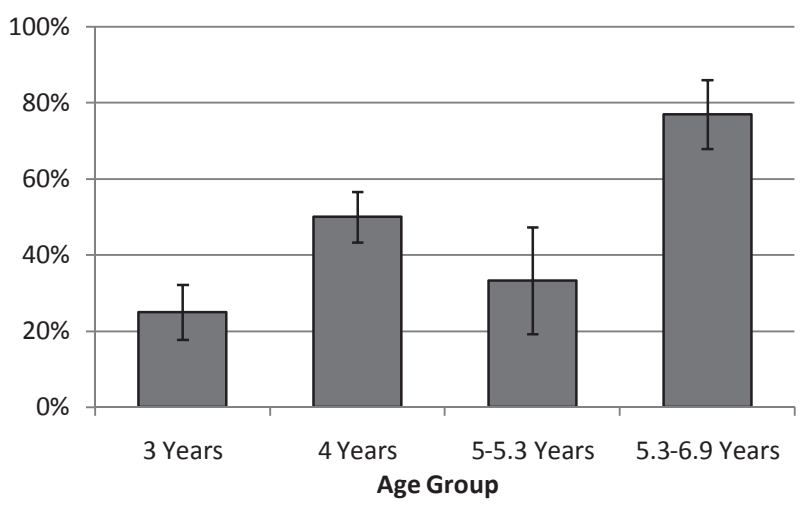

Figure 4. Attributions of knowledge to the negative-trait characters, who had perceptual access to relevant information.

knowledge to the negative-trait characters. A oneway ANOVA revealed a significant difference in attributions of knowledge between the three age groups, $F(2,78)=5.91, p<.01$. Four-year-olds and 5- to 6-year-olds attributed knowledge to the negative-trait characters significantly more than did 3 -year-olds ( $p s=.05$ and .003 , respectively, according to Tukey HSD pairwise comparisons). Across the whole sample, there was an age-graded increase in correct attributions of knowledge to the negativetrait characters, $r(79)=.34, p<.01$.

In prior studies, when characters do not possess traits, children as young as 3 years attribute knowledge to characters who perceive information, but not to those who do not perceive the information (e.g., Pratt \& Bryant, 1990). However, our 3-year-olds often reported, above chance, that the positive-trait characters knew the contents of the closed box, even though those characters never looked inside the box, $t(24)=-3.39, p<.01$. Four-year-olds performed at chance, $t(31)=0.00$, ns. The oldest group as a whole performed accurately across $62 \%$ of the trials, but this was no different from chance, $t(23)=1.46, n s$. Note that our oldest group included children ranging in age from 5 years to nearly 7 years. Inspection of the data suggested that the very oldest children were consistently accurate on this task. To confirm this, we examined the oldest $20 \%$ of our sample $(n=16$; age range $=63.50$ 82.50 months). These children accurately attributed knowledge to the negative-trait characters for $77 \%$ of the trials, and their performance was significantly above chance, $t(15)=3.01, p<.01$.

This initial portion of the knowledge task concerned simply children's attribution of knowledge to the characters. A further important question concerns children's endorsement of the testimony provided by the positive-trait/ignorant versus negative-trait/knowledgeable characters. Following children's decisions about the informants' knowledge, for each trait pair, both informants provided testimony about the closed box's contents and children chose to endorse information provided by one of the informants. One child, a 3-year-old, did not provide an answer to this question for the honestdishonest pair. An initial one-way ANOVA assessing the frequency with which children endorsed the positive-trait (though ignorant) informants' testimony revealed no significant difference between the three age groups, $F(2,78)=1.75$, ns (3-yearolds: $57 \%$; 4-year-olds: $71 \%$; 5- to 6 -year-olds: $71 \%$ ).

Children's trust in the positive-trait informants' testimony depended upon whether they attributed knowledge to those informants. This pattern was especially clear for nice-mean and honest-dishonest pairs of informants. Children who correctly identified that the mean informant was knowledgeable were less likely to endorse the nice informant's subsequent testimony, $\left.\chi^{2}(1)=5.19, p<.05\right)$ and children who identified that the dishonest informant was knowledgeable were less likely to endorse the honest informant's testimony, $\chi^{2}(1)=6.47, p=.01$. Analyzed separately, children who incorrectly attributed knowledge to the nice and honest informants endorsed their subsequent testimony at levels above chance (nice: $77 \%$, binomial $p<.001$; honest: $77 \%$, binomial $p<.001$ ). In contrast, children who were correct in not granting knowledge to the nice and honest informants did not endorse their testimony above chance (nice: $53 \%$, binomial $p=.871$; honest: $50 \%$, binomial $p=1.00$ ). A different pattern emerged for the smart-not-smart pair. Children were equally trusting of the smart character's testimony regardless of whether they understood that he lacked the critical knowledge, $\chi^{2}(1)=1.20$, ns; collectively children preferred his testimony $69 \%$ of the time, significantly above chance (binomial $p<.001$ ).

In summary, trust in informants with positive traits was mitigated among children who could identify when those informants lacked relevant knowledge. However one trait in particular-informants' smartness - continued to weigh heavily in children's trust in testimony, even among children who could identify when a smart informant lacked critical knowledge.

\section{Adult Judgments}

In order to validate our intuitions about what a mature pattern of responses would be for these tasks, 26 adults answered identical questions. In the object-naming and the box-contents tasks, these 
adults overwhelmingly preferred to ask the positive-trait informants (nice: $M=100 \%, S D=0 \%$; smart: $M=98 \%, S D=10 \%$; honest: $M=100 \%$, $S D=0 \%)$ and overwhelmingly endorsed their testimony (nice: $M=100 \%, S D=0 \%$; smart: $M=96 \%$, $S D=14 \%$; honest: $M=100 \%, S D=0 \%$ ). For the knowledge task, adults accurately attributed knowledge to the negative-trait informants on $85 \%$ of the trials, significantly above chance, $t(25)=5.35$, $p<.001$. When faced with trusting the testimony of either the positive-trait/ignorant or negative-trait/ knowledgeable informants, adults trusted the positive-trait/ignorant informants at chance $(M=49 \%$, $S D=37 \%$ ).

These data from adults also provided a point of comparison for our oldest children, to determine if our 5- and 6-year-olds were exhibiting an adult-like pattern of responses. Indeed, for the standard ask and endorsement questions (when learning about the novel object and about the contents of the open box), adults' responses were not significantly different from the 5- and 6-year-olds' responses. Thus their data looked essentially identical to that from the 5- to 6-year-olds in Figures 1 and 2. Moreover, for the knowledge task, adults' attribution of knowledge to the negative-trait informants was not significantly different from the 16 oldest children's knowledge attributions. The only difference between the oldest children and adults was that adults were less trusting of the positive-trait/ignorant informants $(M=49 \%, S D=37 \%)$ than were the oldest children $(M=71 \%, S D=36 \%), t(48)=$ 2.13, $p<.05$.

\section{Discussion}

Much of our knowledge is acquired from othersparents, friends, experts, and teachers. These individuals not only differ in their knowledge but also in many other regards, such as their appearance, age, and personality. The extent to which children weigh some of these factors when learning from others has recently received enormous empirical attention (for reviews, see Gelman, 2009; Harris, 2007). In the current study, we assessed the influence of informants' traits on how children seek information, trust testimony, and make inferences about informants' knowledge. We additionally examined how both informants' traits and their access to knowledge simultaneously influence children's trust in testimony.

Our interest in the influence of informants' traits on children's epistemic trust was motivated, in part, by recent studies which collectively demonstrate that, if presented enough consistent data about informants' tendencies, children as young as 3 years selectively trust informants based upon their recent accuracy (e.g., Birch et al., 2008; Pasquini et al., 2007; Scofield \& Behrend, 2008). Some have reasoned that children use informants' recent accuracy to construct "cognitive profiles" regarding informants' epistemic trustworthiness (Harris, 2007). If provided enough converging information about an informant's accuracy, conceivably children may even begin to infer a trait (perhaps smartness), which may then influence children's subsequent epistemic trust. In the current study, we took a direct approach to assessing the influence of informants' traits on children's trust-we used a paradigm in which characters were assigned trait labels, the labeled traits were described, characters behaved in accordance with their trait labels, and children were reminded about the characters' traits. We found that children as young as 3 years of age, tend to ask and endorse information provided by smart informants rather than informants who are not smart. We also found that preschoolers prefer to ask and endorse information provided by informants who are nice - a less epistemically relevant trait. Although 3-year-olds were as trusting of nice informants as they were the other positive-trait informants, children were not significantly more trusting of the nice (vs. mean) informant until 4 years, and overall children preferred to ask as opposed to endorse the nice informant.

More novel, we assessed children's sensitivity to another trait that is of particular import when considering the quality of someone's testimony-honesty. The influence of informants' honesty on children's knowledge acquisition has received surprisingly little attention in the literature, with the few available studies suggesting that children do not begin to consider informants' honesty until age 4 or later (Mascaro \& Sperber, 2009; Vanderbilt et al., 2011). However, using the same experimental paradigm employed for the other traits-which included two informants who provided conflicting testimony-we found that children as young as 3 years of age also prefer to ask and endorse testimony provided by honest (as opposed to dishonest) informants. What likely accounts for discrepancies between findings is that prior studies required that children disregard information or instructions provided by a single informant, tasks that children may have difficulty with regardless of informants' specific traits (Jaswal et al., 2010; Reed et al., 1984; Strommen, 1973). Thus, prior studies appear to 
have underestimated children's consideration of informants' honesty. In general, informants' traitsespecially smartness and honesty-can weigh heavily when young children consider the quality of testimony.

Thus, the current results demonstrate that others' traits influence children's epistemic trust. We demonstrated this by pitting characters with traits of contrasting valence - for example, mean versus niceagainst one another. With our procedures, it is unclear whether children trusted positive-trait informants, distrusted negative-trait informants, or both. Future studies could more meticulously assess the driving forces behind the effects found for each of the trait pairs. For example, positive- and negativetrait informants can be pitted against neutral informants, to determine whether children's responses are driven entirely by the positive-trait informants, entirely by the negative-trait informants, or by a combination of the two.

One possible interpretation of our results is that children chose informants and testimony based upon a general characterization of the smart, honest, and nice informants as equally positive, without considering their particular traits. However, the variability in 3-year-olds' willingness to affiliate with each of the six informants suggests that children did not consider the three positive-trait informants one and the same. The affiliation data also allowed us to examine relations between preschoolers' testimony judgments and their more general attraction or aversion to informants. Several studies pitting accurate informants against inaccurate informants have demonstrated that children's preference for testimony cannot be attributed to children's general attraction to accurate informants (e.g., Birch et al., 2008; Jaswal \& Neely, 2006). The results of the current study likewise demonstrate that a general attraction to informants with certain traits is not solely responsible for children's trust in their testimony. Over half of the 3-year-olds wanted to be friends with the informant who was not smart, yet they typically chose to ask and endorse information provided by the smart informant. Moreover, 3-year-olds were equally willing to be friends with the honest and dishonest informants, yet they preferred to ask the honest informant for information and they favored his testimony; and children were equally willing to trust information provided by the honest informant regardless of whether they wanted to be his friend. For all age groups, decisions to affiliate with informants were uncorrelated with children's endorsement of informants' testimony, also indicating that a general desire to affiliate was not solely responsible for children's trust in testimony. However, the affiliation questions and testimony questions had different formatsfor each pair, children could choose to be friends with one, both, or neither of the informants, but had to trust the testimony of just one informant. To further examine relations between children's affiliation preferences and trust in testimony, future studies can use a forced-choice format where children choose to be friends with just one of the two informants.

An important focus of our research was children's consideration not only of informants' traits but of their knowledge as well. Here, our most intriguing finding was that traits can influence the very knowledge that young children attribute to informants. Indeed, 3-year-olds overwhelmingly used the valence of informants' traits, rather than informants' perceptual access to relevant information, to infer informants' knowledge. This was true for a trait that is often associated with the quality of one's knowledge (smartness) as well as two traits that seem more morally relevant and less epistemically relevant (i.e., not typically associated the quality of individuals' knowledge), honesty and kindness. Only the oldest children (5- and 6-yearolds) and adults consistently differentiated between the valence of informants' traits and the quality of their knowledge. Thus, although 3- and 4-year-olds are fully aware of the link between perceiving information and knowing that information (e.g., Pratt \& Bryant, 1990), they sometimes disregard people's perceptual access to information when those people have certain traits, and instead (inaccurately) use the valence of those traits to guide epistemic inferences. Others' traits carry great inductive potential when considering their intentions, emotions, and behavior (Heyman, 2009), and young children appear to use trait information even when reasoning about others' knowledge.

In a study with seemingly contrasting results, Brosseau-Liard and Birch (2010) found that 4-yearolds did not attribute greater general knowledge (e.g., knowledge of words) or situation-specific knowledge (e.g., "Who knows where I put my books?") to a recently accurate character. Likewise, Brosseau-Liard and Birch (2011) demonstrated that preschoolers show no preference for the testimony of accurate (vs. inaccurate) informants when both informants report on the contents of a box that neither informant has looked in. The results of these studies are likely a product of children only having been given information about informants' recent accuracy (which may or may not reflect an 
underlying trait), rather than the rich and more direct information that we provided about our informants' traits. Young children in particular have difficulty predicting people's future behavior based upon their prior trait-related behavior, but can do so when people are assigned trait labels (Heyman \& Gelman, 1999, 2000; Liu et al., 2007). We anticipated that this may also be the case with regard to children's use of trait information to guide their epistemic trust and epistemic inferences. Thus, in addition to engaging in trait-consistent behavior, our informants were assigned trait labels and we described to children what those labels meant.

Turning to our results on how children simultaneously consider informants' knowledge access and traits when trusting testimony, we found that children who reported (incorrectly) that nice and honest informants were knowledgeable about key information (when in fact those informants had not even perceived the information) tended to endorse those informants' testimony. In contrast, children who understood that those informants were not knowledgeable were less trusting of their testimony. Intriguingly, a different pattern emerged for the smart informant-children trusted his testimony even when they understood that he was not knowledgeable. Thus, when learning from others, young children may weigh informants' general intelligence more strongly than informants' specific knowledge, especially in cases where a smart informant is pitted against an informant who is not smart.

The early tendency to attribute knowledge to individuals with positive qualities should be considered when interpreting other findings on young children's preference for certain informants' testimony. For example, Corriveau and Harris (2009) demonstrated that 3- and 4-year-olds prefer to ask and endorse information provided by teachers they know well, and continue to trust these teachers even if they had just provided inaccurate information. It is not until age five that children prefer information from unfamiliar yet accurate teachers. Corriveau and Harris provide four potential interpretations of their findings, and settle upon a "halo effect" account-children judge familiar people as positive on multiple dimensions, including likeability, competence, and trustworthiness. Such a halo effect may indeed be at work (see Brosseau-Liard \& Birch, 2010), and we would add that the quality of informants' knowledge (including situationspecific knowledge) may be included within such a halo.

Our data also lend support to a complementary account of Corriveau and Harris's (2009) results: given extended experience with their teachers, children appreciate that they possess certain traits, specifically intelligence - teachers are typically knowledgeable, provide accurate information, can figure out new problems, and so on. As we argued earlier, young children in particular require much detail about someone's tendencies in order to infer their traits, and thus a few recent instances of the familiar teacher's inaccuracy may have not been enough information for the youngest children to understand that she possessed some fundamental cognitive limitation, especially when they have so much prior information about the familiar teacher's competence.

In summary, informants' traits can factor strongly into how young children seek and trust testimony. Preschoolers prefer to ask and endorse information provided by people who are nice, smart, and honest, and this is especially the case for the latter two traits. This preference increases throughout the preschool years and is not attributable to a more general desire to affiliate with positive-trait individuals. Moreover, these traits influence the very knowledge that preschoolers attribute to informants. In certain circumstances, young children consider people with positive traits to be knowledgeable even if they clearly do not have access to relevant information. This misattribution of knowledge decreases throughout the preschool years, but is still apparent in 5-year-olds. In young children's evaluation of testimony, informants' epistemically relevant traits can weigh particularly heavily. Indeed, as one example, children continue to trust the testimony of smart (over not smart) informants even when they realize that such informants lack key knowledge.

\section{References}

Alvarez, J. M., Ruble, D. N., \& Bolger, N. (2001). Trait understanding or evaluative reasoning? An analysis of children's behavioral predictions. Child Development, 72, 1409-1425. doi:10.1111/1467-8624.00356

Birch, S. A. J., Vauthier, S. A., \& Bloom, P. (2008). Three and four-year-olds spontaneously use others' past performance to guide their learning. Cognition, 107, 10181034. doi:10.1016/j.cognition.2007.12.008

Brosseau-Liard, P. E., \& Birch, S. A. J. (2010). "I bet you know more and are nicer too!": What children infer from others' accuracy. Developmental Science, 13, 772778. doi:10.1111/j.1467-7687.2009.00932.x

Brosseau-Liard, P. E., \& Birch, S. A. J. (2011). Epistemic states and traits: Preschoolers appreciate the differential informativeness of situation-specific and person-specific 
cues to knowledge. Child Development, 82, 1788-1796. doi:10.1111/j.1467-8624.2011.01662.x

Cain, K. M., Heyman, G. D., \& Walker, M. E. (1997). Preschoolers' ability to make dispositional predictions within and across domains. Social Development, 6, 5375. doi:10.1111/j.1467-9507.1997.tb00094.x

Clément, F., Koenig, M. A., \& Harris, P. L. (2004). The ontogenesis of trust. Mind and Language, 19, 360-379. doi:10.1111/j.0268-1064.2004.00263.x

Corriveau, K., \& Harris, P. L. (2009). Choosing your informant: Weighing familiarity and recent accuracy. Developmental Science, 12, 426-437. doi:10.1111/j.1467-7687.2008.00792.x

Gelman, S. A. (2009). Learning from others: Children's construction of concepts. Annual Review of Psychology, 60, 115-140. doi:10.1146/annurev.psych.59.103006.0936 59

Harris, P. L. (2007). Trust. Developmental Science, 10, 135138. doi:10.1111/j.1467-7687.2007.00575.x

Harris, P. L., \& Koenig, M. A. (2006). Trust in testimony: How children learn about science and religion. Child Development, 77, 505-524. doi:10.1111/j.1467-8624.2006.0 0886.x

Heyman, G. D. (2009). Children's reasoning about traits. In P. J. Bauer (Ed.), Advances in child development and behavior (Vol. 37, pp. 105-143). New York: Academic Press.

Heyman, G. D., \& Gelman, S. A. (1999). The use of trait labels in making psychological inferences. Child Development, 70, 604-619. doi:10.1111/1467-8624.00044

Heyman, G. D., \& Gelman, S. A. (2000). Preschool children's use of trait labels to make inductive inferences. Journal of Experimental Child Psychology, 77, 1-19. doi:10. 1006/jecp. 1999.2555

Jaswal, V. K., Croft, A. C., Setia, A. R., \& Cole, C. A. (2010). Young children have a specific, highly robust bias to trust testimony. Psychological Science, 21, 15411547. doi:10.1177/0956797610383438

Jaswal, V. K., \& Malone, L. S. (2007). Turning believers into skeptics: 3-year-olds' sensitivity to cues to speaker credibility. Journal of Cognition and Development, 8, 263283. doi:10.1080/15248370701446392

Jaswal, V. K., \& Neely, L. A. (2006). Adults don't always know best: Preschoolers use past reliability over age when learning new words. Psychological Science, 17, 757758. doi:10.1111/j.1467-9280.2006.01778.x

Koenig, M. A., Clément, F., \& Harris, P. L. (2004). Trust in testimony: Children's use of true and false statements. Psychological Science, 694-698, doi:10.1111/j. 0956-7976.2004.00742.x

Koenig, M. A., \& Harris, P. L. (2005). Preschoolers mistrust ignorant and inaccurate speakers. Child Development, 76, 1261-1277. doi:10.1111/j.1467-8624.2005.00849.x

Liu, D., Gelman, S. A., \& Wellman, H. M. (2007). Components of young children's trait understanding: Behavior-to-trait inferences and trait-to-behavior predictions. Child Development, 78, 1543-1558. doi:10.1111/j.14678624.2007.01082.x
Lucas, A. J., \& Lewis, C. (2010). Should we trust experiments on trust? Human Development, 53, 167-172. doi:10.1159/000320044

Mascaro, O., \& Sperber, D. (2009). The moral, epistemic, and mindreading components of children's vigilance towards deception. Cognition, 112, 367-380. doi:10.1016/ j.cognition.2009.05.012

Moore, C., Bryant, D., \& Furrow, D. (1989). Mental terms and the development of certainty. Child Development, 60, 167-171.

Nurmsoo, E., \& Robinson, E. J. (2009). Children's trust in previously inaccurate informants who were well or poorly informed: When past errors can be excused. Child Development, 80, 23-27. doi:10.1111/j.1467-8624.2008.01243

Pasquini, E. S., Corriveau, K. H., Koenig, M., \& Harris, P. L. (2007). Preschoolers monitor the relative accuracy of informants. Developmental Psychology, 43, 1216-1226. doi:10.1037/0012-1649.43.5.1216

Pratt, C., \& Bryant, P. (1990). Young children understand that looking leads to knowing (so long as they are looking into a single barrel). Child Development, 61, 973982. doi:10.1111/j.1467-8624.1990.tb02835.x

Reed, M. A., Pien, D. L., \& Rothbart, M. K. (1984). Inhibitory self-control in preschool children. Merrill-Palmer Quarterly, 30, 131-147.

Robinson, E. J., Champion, H., \& Mitchell, P. (1999). Children's ability to infer utterance veracity from speaker informedness. Developmental Psychology, 35, 535-546. doi:10.1037/0012-1649.35.2.535

Robinson, E. J., \& Nurmsoo, E. (2009). When do children learn from unreliable speakers? Cognitive Development, 24, 16-22. doi:10.1016/j.cogdev.2008.08.001

Sabbagh, M. A., \& Baldwin, D. A. (2001). Learning words from knowledgeable versus ignorant speakers: Links between preschoolers' theory of mind and semantic development. Child Development, 72, 1054-1070. doi:10. 1111/1467-8624.00334

Scofield, J., \& Behrend, D. A. (2008). Learning words from reliable and unreliable speakers. Cognitive Development, 23, 278-290. doi:10.1016/j.cogdev.2008.01.003

Siegal, M., \& Peterson, C. C. (1996). Breaking the mold: A fresh look at children's understanding of questions about lies and mistakes. Developmental Psychology, 32, 322-334. doi:10.1037/0012-1649.32.2.322

Siegal, M., \& Peterson, C. C. (1998). Preschoolers' understanding of lies and innocent and negligent mistakes. Developmental Psychology, 34, 332-341. doi:10.1037/ 0012-1649.34.2.332

Stipek, D. J., \& Daniels, D. H. (1990). Children's use of dispositional attributions in predicting the performance and behavior of classmates. Journal of Applied Developmental Psychology, 11, 13-28. doi:10.1016/0193-3973(90)90029-J

Strommen, E. A. (1973). Verbal self-regulation in a children's game: Impulsive errors on "Simon says." Child Development, 44, 849-853.

Vanderbilt, K. E., Liu, D., \& Heyman, G. D. (2011). The development of distrust. Child Development, 82, 1372 1380. doi:10.1111/j.1467-8624.2011.01629.x 


\section{Appendix}

\section{Informant Introductions}

\section{Nice}

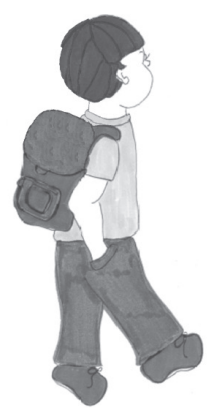

This is Neal. Neal is a boy who does nice things for people. Neal is nice.

Here's Neal at school. He is walking down the hall.
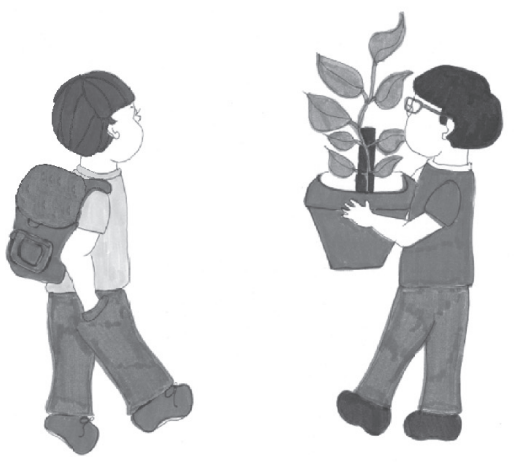

He walks by a boy carrying a plant.

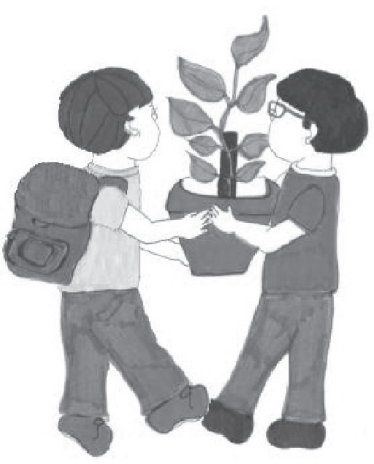

Look, Neal helps the boy carry the plant. Remember, Neal is nice.
Mean

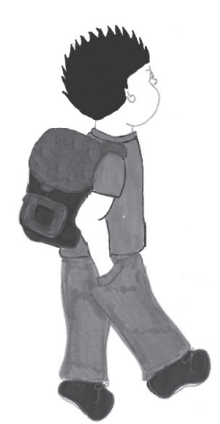

This is Mike. Mike is a boy who does mean things to people. Mike is mean.

Here's Mike at school. He is walking down the hall.
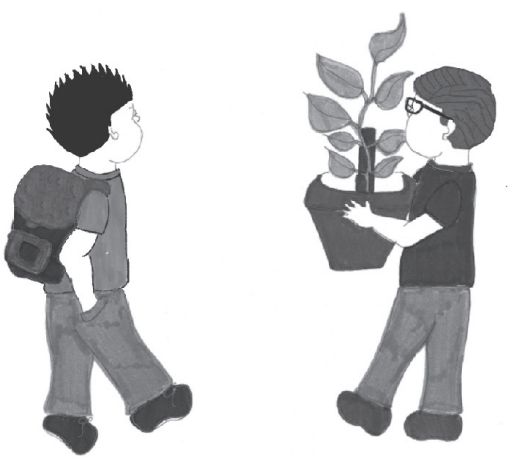

He walks by a boy carrying a plant.

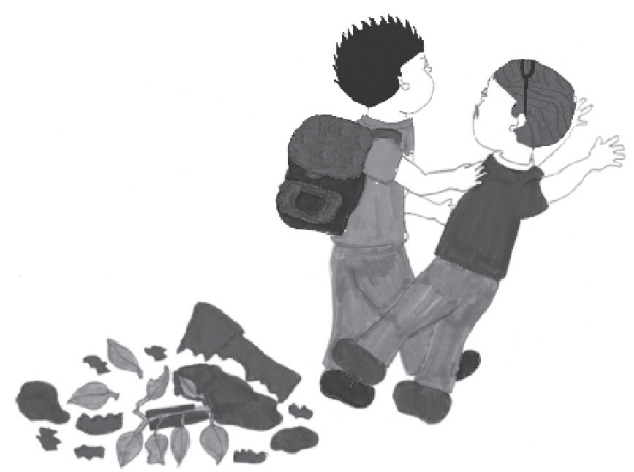

Look, Mike pushes the boy and his plant falls on the floor and breaks.

Remember, Mike is mean. 


\section{Smart}

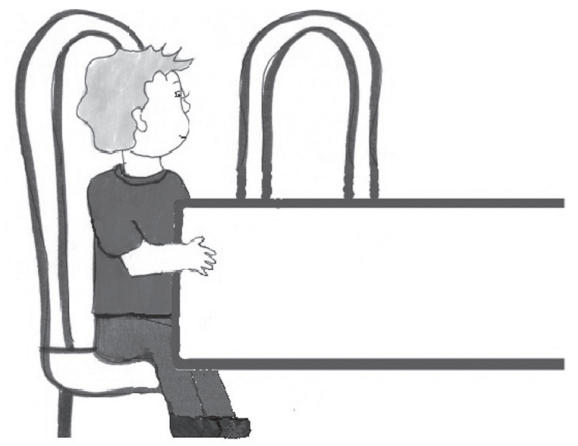

This is Sam. Sam is a boy who gives right answers. Sam is smart.

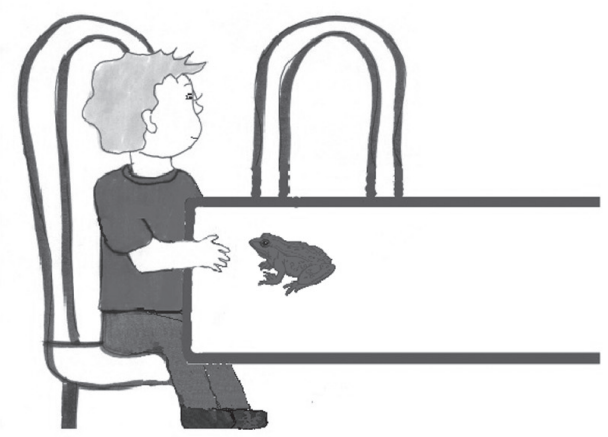

Here's Sam sitting at a table. Look at what's on the table.

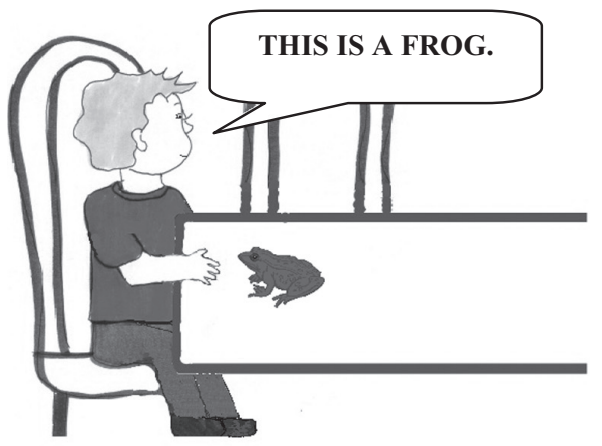

Sam says: "This is a frog."

Remember, Sam is smart.
Not Smart

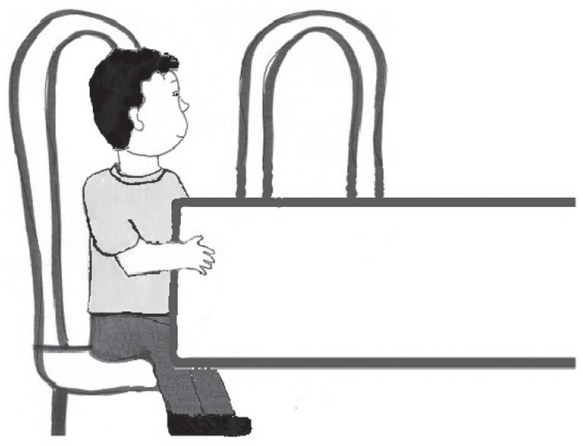

This is Noah. Noah is a boy who gives wrong answers. Noah is not smart.

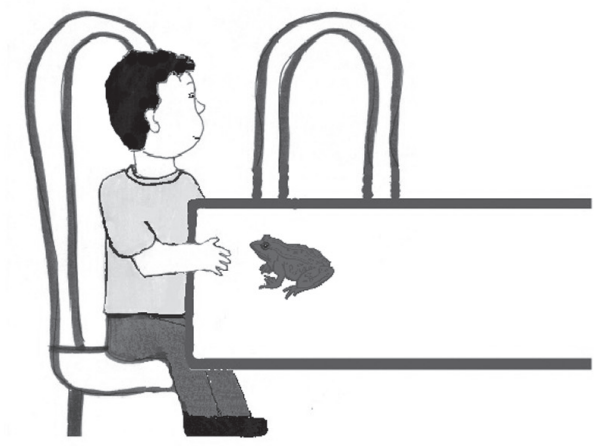

Here's Noah sitting at a table. Look at what's on the table.

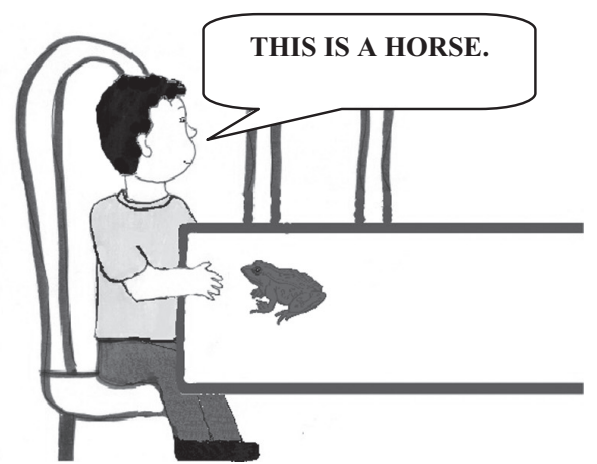

Noah says: "This is a horse."

Remember, Noah is not smart. 


\section{Honest}

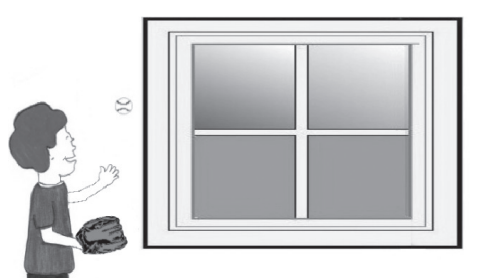

This is Tom. Tom is a boy who tells the truth. Tom is truthful. Here's Tom throwing a ball in his house.

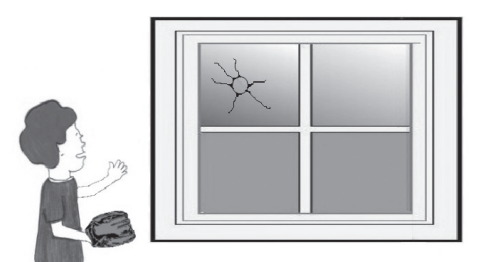

Look, Tom accidentally throws the ball at the window and the window breaks.

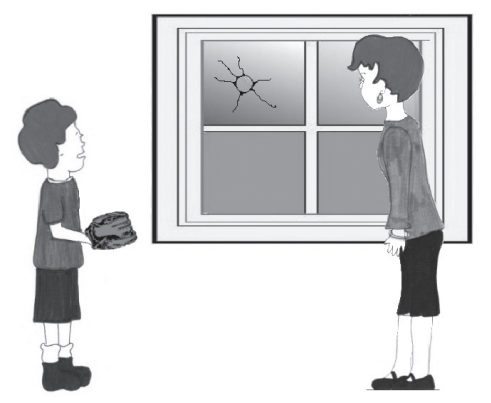

Tom's Mom comes in the room and asks, "Tom, did you break the window?"

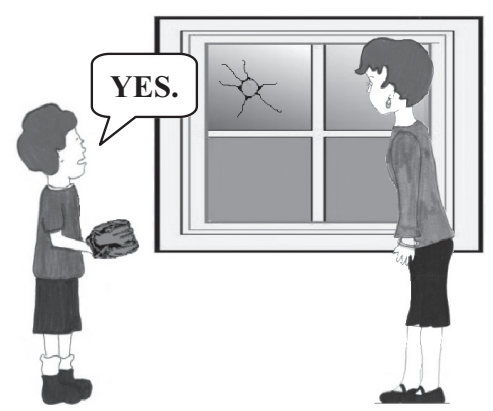

Tom says, "Yes." Remember, Tom is truthful.

\section{Dishonest}

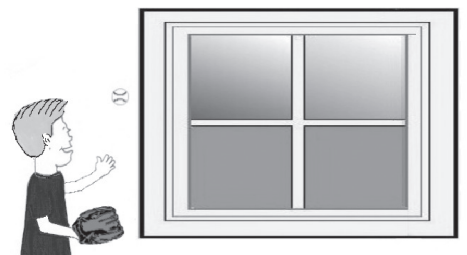

This is Larry. Larry is a boy who tells lies. Larry is a liar. Here's Larry throwing a ball in his house.
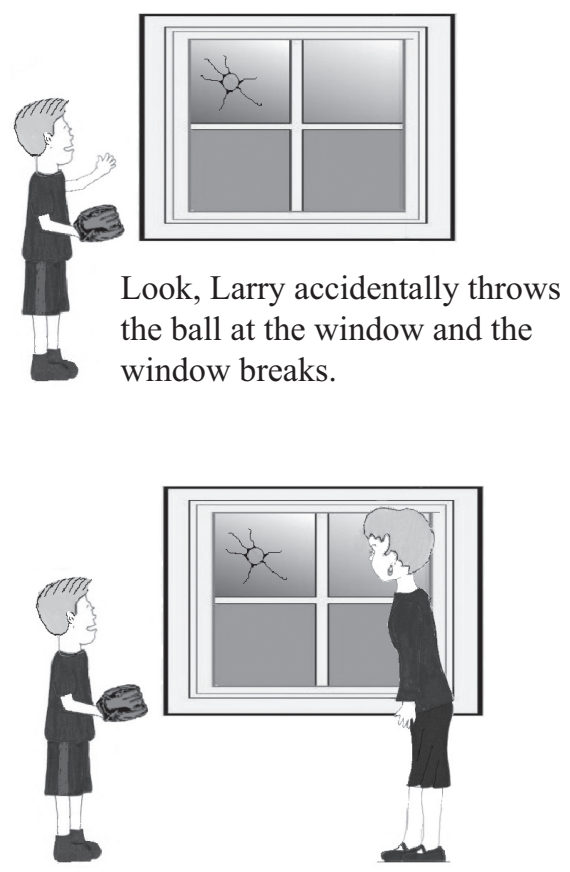

Larry's Mom comes in the room and asks, "Larry, did you break the window?"

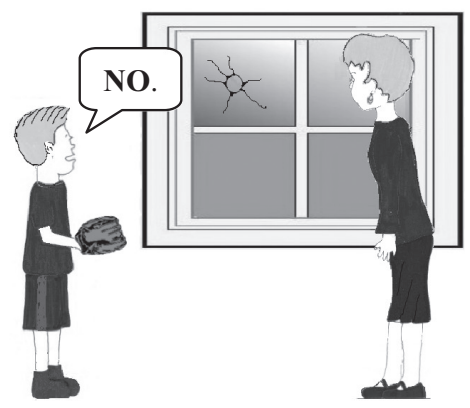

Larry says, "No." Remember, Larry is a liar. 